\title{
Phenylboronic Acid/CuSO 4 as an Efficient Catalyst for the Synthesis of 1,4-Disubstituted-1,2,3-Triazoles from Terminal Acetylenes and Alkyl Azides
}

\author{
José Emilio de la Cerda-Pedro, ${ }^{1}$ Susana Rojas-Lima, ${ }^{1}$ Rosa Santillan ${ }^{2}$ and Heraclio López-Ruiz ${ }^{1 *}$ \\ 1 Área Académica de Química (AAQ), Universidad Autónoma del Estado de Hidalgo (UAEH), Ciudad Universitaria, Carretera \\ Pachuca-Tulancingo Km 4.5, C.P 42184 Mineral de la Reforma, Hidalgo, México. Dirección: *corresponding author: \\ heraclio@uaeh.edu.mx \\ 2 Departamento de Química, Centro de Investigación y de Estudios Avanzados del Instituto Politécnico Nacional, A.P. 14-740, \\ Avenida IPN 2508, Esquina Ticoman, C.P. 07000 México, D.F., México.
}

Received January 27 $7^{\text {th }}$ 2015; Accepted March $9^{\text {th }}, 2015$

\begin{abstract}
The synthesis of 1,4-disubstituted-1,2,3-triazoles from alkyl azides and terminal alkynes at room temperature and under microwave heating was attained using $\mathrm{Cu}(\mathrm{I})$, generated in-situ from copper(II) sulfate and phenylboronic acid, as catalyst. Twelve new triazoles were obtained in moderate to good yields (53-98\%), and the products were obtained by crystallization from the mixture reaction without further purification.
\end{abstract}

Key words: triazoles, phenylboronic acid, $\mathrm{CuSO}_{4}$, Microwave irradiation.

\section{Introduction}

The $\mathrm{Cu}(\mathrm{I})$-catalyzed azide-alkyne cycloaddition reaction (CuAAC) has become the preferred synthetic route to 1,4-disubstituted 1,2,3-triazoles, some of which have interesting biological properties and/or applications in drug design [1-3]. Because of the thermodynamic instability of $\mathrm{Cu}(\mathrm{I})$, $\mathrm{Cu}$ (II) is usually reduced in situ, by the addition of reducing agents such as sodium ascorbate [4], glucose in the presence of Fehling's reagent [5], or $\mathrm{NaN}_{3}$ [6], and $\mathrm{NaCN}$ [7]. In general, longer reaction times are required when the $\mathrm{Cu}(\mathrm{II}) /$ ascorbate process is used, therefore we believe there is still potential for further development in this reaction.

The readily available phenylboronic acid [8] is stable to heat, air, and moisture, making it an attractive and valuable precursor of phenol by its oxidation with $\mathrm{CuSO}_{4}$ [9-10]. Thus, stirring phenylboronic acid in a solvent, followed by addition of $\mathrm{CuSO}_{4}$ produces $\mathrm{Cu}(\mathrm{I})$. We employed this reaction to develop an efficient, synthesis of 1,4-disubstituted-1,2,3-triazoles from alkyl acetylenes that can be effected at room temperature, or more rapidly upon microwave irradiation.

The assistance of aryl boronic acid in the synthesis of triazoles by this route using $\mathrm{Cu}$-catalysts in $\mathrm{H}_{2} \mathrm{O}$ and other solvents has been reported earlier $[6,11]$. However, $\mathrm{Cu}(\mathrm{I})$ generated in this manner has not been used to catalyze the formation of 1,4-disubstituted-1,2,3-triazoles from alkyl azides and mono-substituted acetylenes therefore we describe herein the application of this methodology to the synthesis of new six new triazole derivatives.
Resumen. Se describe la síntesis de 1,2,3-triazoles-1,4-disustituidos a partir de alquilazidas y alquinos terminales a temperatura ambiente y calentamiento por microondas empleando $\mathrm{Cu}(\mathrm{I})$ generado in-situ a partir de sulfato de cobre(II) y ácido fenilborónico, como catalizador. Bajo estas condiciones se prepararon doce triazoles nuevos en rendimientos de moderados a buenos (53-98\%), que cristalizan de la mezcla de reacción sin purificación adicional.

Palabras clave: triazoles, ácido fenilborónico, $\mathrm{CuSO}_{4}$, irradiación de microondas.

\section{Results and discussion}

Initially, studies were carried out using phenyl acetylene and benzyl azide in the presence of varying amounts of $\mathrm{CuSO}_{4}$ and $\mathrm{PhB}(\mathrm{OH})_{2}$ at room temperature. Therefore, a 1:1 mixture of $\mathrm{H}_{2} \mathrm{O} / \mathrm{i} \mathrm{PrOH}$ was chosen as the solvent, and several experiments were carried out (see table 1). The data (Table 1) clearly show that the best conditions for the formation of $\mathbf{3 a}$ involved

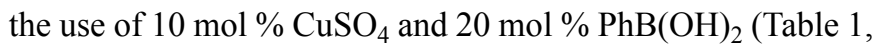
entry 5). We also evaluated the solvent effect, although previous studies from our laboratory have documented the advantage of a $\mathrm{H}_{2} \mathrm{O} / \mathrm{i} \mathrm{PrOH}(1: 1)$ solvent mixture [7,12]. In addition, the influence of different bases was investigated finding that the highest yields were obtained using a molar excess of $\mathrm{Et}_{3} \mathrm{~N}$. Under his conditions, the cycloaddition reaction is favored by minimizing the formation of by products, also it prevents degradation of $\mathrm{Cu}(\mathrm{I})$ by oxidation or switching and helps to solubilize the copper in the reaction medium [13].

After optimization of the conditions, the scope of the reaction in regard to alkyne and azide structures was explored by reacting various azides with terminal alkynes in the presence of $\mathrm{CuSO}_{4}(10 \mathrm{~mol} \%)$ and $\mathrm{PhB}(\mathrm{OH})_{2}(20 \mathrm{~mol} \%)$. The results are summarized in Table 3. It is obvious from these data that a wide variety of azides possessing different functional groups are tolerated. The reaction also showed considerable tolerance for substituents in the phenyl alkynes (Table 3). Both electron donating and electron withdrawing substituents in the phenyl alkynes led to the desired products in high yields with little differences in reaction times. In contrast, both the reaction of 


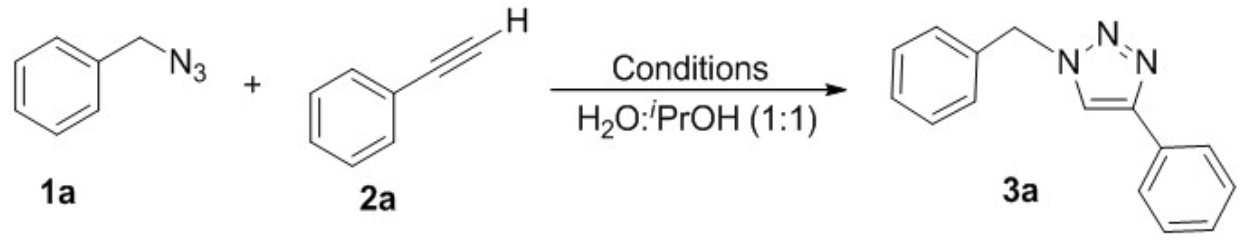

Scheme 1. Search for optimal conditions.<smiles>N#Cc1ccc(C#Cc2ccc(-c3cn(Cc4ccccc4)nn3)cc2)cc1</smiles>

Scheme 2. Synthesis of compound $3 c$ and bistriazole 4.

Table 1. Catalyst screening for the synthesis of $\mathbf{3 a}$.

\begin{tabular}{cccc}
\hline & \multicolumn{2}{c}{ Conditions } & \\
\cline { 2 - 3 } Entry & $\begin{array}{c}\mathrm{CuSO}_{4} \\
(\mathrm{~mol} \%)\end{array}$ & $\begin{array}{c}\mathrm{PhB}(\mathrm{OH})_{2} \\
(\mathrm{~mol} \%)\end{array}$ & $\begin{array}{c}\text { Yield } \\
(\%)^{\mathrm{b}}\end{array}$ \\
\hline 1 & 10 & 10 & $\mathrm{NR}^{\mathrm{c}}$ \\
2 & 10 & 5 & $14^{\mathrm{b}}$ \\
3 & 10 & 7 & $29^{\mathrm{b}}$ \\
4 & 10 & 10 & $54^{\mathrm{b}}$ \\
5 & 10 & 20 & $85^{\mathrm{b}}$ \\
6 & 10 & ---- & $\mathrm{NR}$ \\
\hline
\end{tabular}

a All reactions were carried out using $0.75 \mathrm{mmol}$ of benzyl azide, $0.75 \mathrm{mmol}$ of phenylacetylene and $1 \mathrm{~mL}^{\circ} \mathrm{Et}_{3} \mathrm{~N}$ in $2 \mathrm{~mL}$ of ${ }^{i} \mathrm{Pr}-$ $\mathrm{OH} / \mathrm{H}_{2} \mathrm{O}(1: 1)$ at room temperature during $5 \mathrm{~h}$.

$\mathrm{b}$ isolated yield after purification via flash chromatography.

c without $\mathrm{Et}_{3} \mathrm{~N}$ phenylacetylene and 1-chloro-4-ethynylbenzene with 5-azido-2-(2-methoxyphenyl)benzoxazole gave modest yields of the expected products $\mathbf{3 g}$ and $\mathbf{3 h}$ respectively, in spite of increased reactions times (Table 3, entries 7-8). However, when reactions with benzyl azide and 4-ethynylbenzonitrile were carried out using catalytic $\mathrm{CuSO}_{4}$ in the presence of phenylboronic acid, a mixture of triazole and bistriazole was obtained in agreement with the observations of Burgess [14] and Cuevas-Yañez [15] (Scheme 2). We rationalized the formation of this by-product on the basis of the reducing power of $\mathrm{PhB}(\mathrm{OH})_{2}$ at room temperature. The structures of most of the 1,2,3-triazoles was supported by the usual spectroscopic data. In contrast, the structures of triazole $\mathbf{3 h}$ and bistriazole $\mathbf{4}$ were unequivocally established by X-ray crystallography (Fig. 1) [16].

Microwave irradiation has revolutionized modern organic synthesis due the energy saving, shortened reaction times, and the formation of fewer side products [17]. Accordingly, the

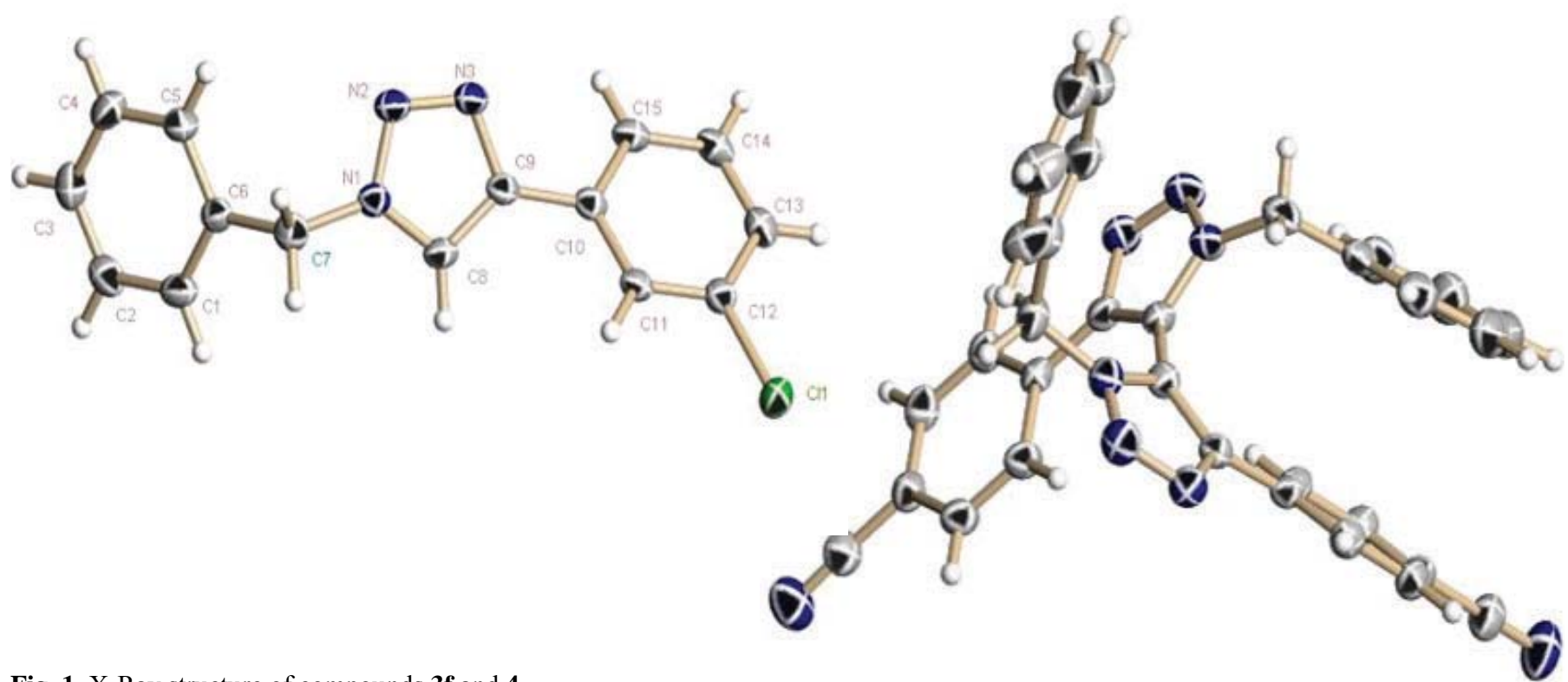

Fig. 1. X-Ray structure of compounds $3 f$ and 4. 
methodology already described above was explored under microwave irradiation. Thus, the same reactions between azides and terminal alkynes using $\mathrm{Cu}(\mathrm{I})$ generated with $\mathrm{CuSO}_{4}$ and phenylboronic acid were run in water $/{ }^{i} \mathrm{PrOH}(1: 1)$ using microwave irradiation at $100 \mathrm{~W}$ and $125^{\circ} \mathrm{C}$ (Table 2). The data clearly show that the best conditions for the formation of $\mathbf{3 a}$ involved the use of $\mathrm{CuSO}_{4}(10 \mathrm{~mol} \%)$ and $\mathrm{PhB}(\mathrm{OH})_{2}(20$ mol\%) at $100 \mathrm{~W}$ and $125^{\circ} \mathrm{C}$ for $10 \mathrm{~min}$ (Table 2, entry 3). Increasing the reaction time to $30 \mathrm{~min}$ led to a decrease in yield. With these optimized reaction conditions in hand, the scope and generality of this protocol was examined employing benzyl azide and various aromatic azides with terminal alkynes (Table 3). When we used benzyl azide with different phenylalkynes the reaction took only 10 min (Table 3, entries 1-6). However, the reaction of phenylacetylene, 1-chloro-4-ethynylbenzene and 4-ethynylanisole with 5-azido-2-(2-methoxyphenyl)benzoxazole required $15 \mathrm{~min}$ to give good product yields (Table 3, entries 7-9). In contrast to the room temperature results described above, no diyne or bis-triazole formation was observed under these conditions.

The role of phenylboronic acid is to reduce copper(II) sulfate to $\mathrm{Cu}(\mathrm{I})$, which is responsible for catalyzing the reaction, obtaining only the 1,4-disubstituted-1,2,3-triazoles in excellent yields. A possible mechanism for the catalytic $\mathrm{CuSO}_{4} /$ $\mathrm{PhB}(\mathrm{OH})_{2}$ reaction is depicted in Scheme 3 [18].

The structure of most 1,2,3-triazoles was supported by the usual spectroscopic data and by X-ray crystallography.

\section{Conclusions}

In summary, a very efficient and straightforward procedure for the regioselective synthesis of alkyl and aryl-1,2,3-triazoles has been developed using commercially available $\mathrm{CuSO}_{4}(10$ mol\%) and $\mathrm{PhB}(\mathrm{OH})_{2}(20 \mathrm{~mol} \%)$, at room temperature or at $125^{\circ} \mathrm{C}$ by microwave irradiation at $100 \mathrm{~W}$. Microwave irradiation dramatically decreases reaction time from hours to minutes with excellent yields. 1,2,3-Triazoles thus produced often crystallize from the reaction mixture and do not require any further purification.

\section{Experimental}

Unless otherwise noted, materials were obtained from commercial suppliers and used without further purification. Thin
Table 2. Catalyst screening for the synthesis of $\mathbf{3 a}$ in MW irradiation. ${ }^{\mathrm{a}}$

\begin{tabular}{|c|c|c|c|c|}
\hline \multirow[b]{2}{*}{ Entry } & \multicolumn{2}{|c|}{ Conditions } & \multirow{2}{*}{$\begin{array}{l}\text { Time } \\
(\min .)\end{array}$} & \multirow{2}{*}{$\begin{array}{l}\text { Yield } \\
(\%)^{\mathrm{b}}\end{array}$} \\
\hline & $\begin{array}{c}\mathrm{CuSO}_{4} \\
(\mathrm{~mol} \%)\end{array}$ & $\begin{array}{c}\mathrm{PhB}(\mathrm{OH})_{2} \\
(\mathrm{~mol} \%)\end{array}$ & & \\
\hline 1 & -- & -- & 10 & NR \\
\hline 2 & 5 & 10 & 10 & 89 \\
\hline 3 & 10 & 20 & 10 & 97 \\
\hline 4 & 10 & -- & 10 & 53 \\
\hline 5 & -- & 20 & 10 & NR \\
\hline 6 & 10 & 20 & 30 & 96 \\
\hline
\end{tabular}

a All reactions were carried out using $0.75 \mathrm{mmol}$ of benzyl azide, $0.75 \mathrm{mmol}$ of phenylacetylene and $1 \mathrm{~mL}$ of Et ${ }_{3} \mathrm{~N}$ in $2 \mathrm{~mL}$ of ${ }^{i} \mathrm{Pr}-$ $\mathrm{OH}: \mathrm{H}_{2} \mathrm{O}(1: 1)$ at $100 \mathrm{~W}$ and $125^{\circ} \mathrm{C}$.

$\mathrm{b}$ isolated yields purified by crystallization.

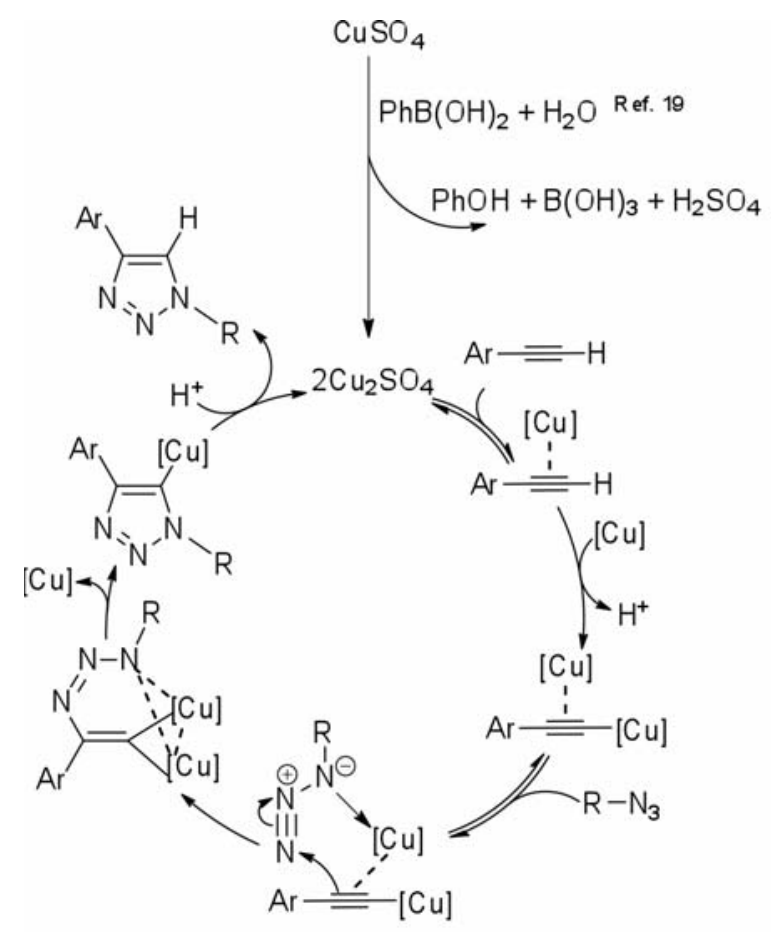

Scheme 3. Postulated Mechanism.
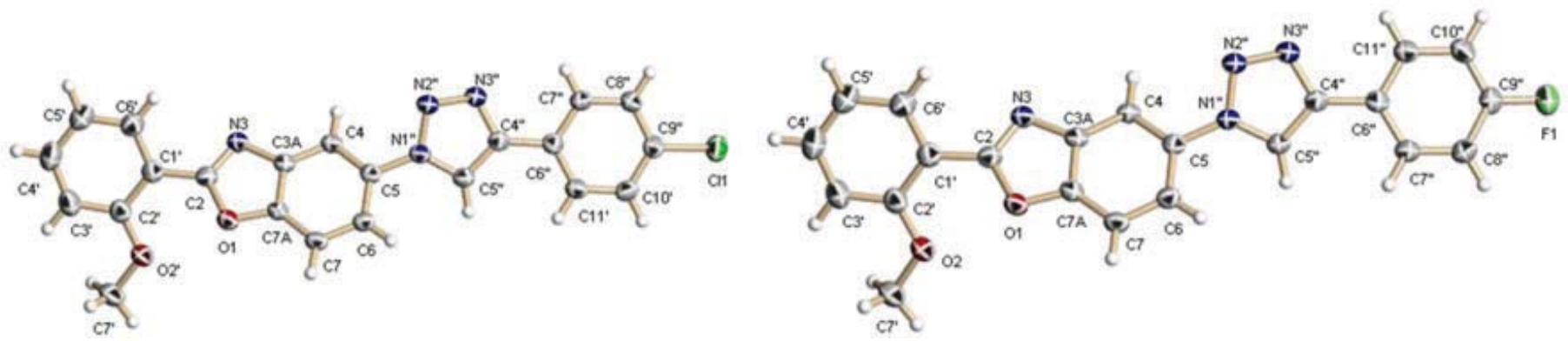

Fig. 2. X-Ray structure of compounds $\mathbf{3 h}$ and $\mathbf{3 j}$. 
Phenylboronic Acid/CuSO 4 as an Efficient Catalyst for the Synthesis of 1,4-Disubstituted-1,2,3-Triazoles from Terminal Acetylenes...

Table 3: Synthesis of 1,4-disubstituted-1,2,3-triazoles from alkyl or aryl azides and terminal alkynes at room temperature or using MW.

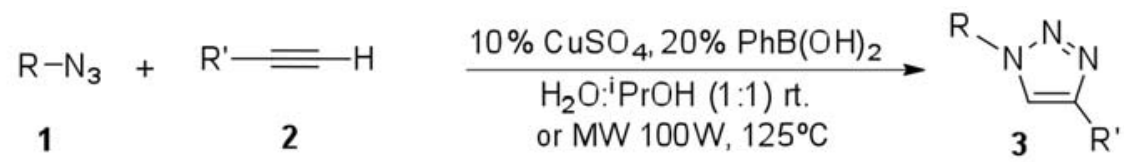

\begin{tabular}{|c|c|c|c|c|c|c|}
\hline \multirow{2}{*}{ Entry } & \multirow{2}{*}{ Product } & \multicolumn{2}{|c|}{ Yield $(\%)^{c}$} & \multicolumn{2}{|c|}{ Time (min.) } & \multirow{2}{*}{$\begin{array}{c}\text { m.p. }\left({ }^{\circ} \mathrm{C}\right) \\
\text { [Ref.] }\end{array}$} \\
\hline & & $\mathrm{MW}^{\mathrm{a}}$ & r.t. ${ }^{b}$ & MW & r.t. & \\
\hline 1 & & 97 & 85 & 10 & 300 & $\begin{array}{c}129-131 \\
{[7]}\end{array}$ \\
\hline 2 & & 96 & 93 & 10 & 300 & $\begin{array}{c}181-182 \\
{[7]}\end{array}$ \\
\hline 3 & & 89 & 78 & 10 & 300 & $\begin{array}{c}144-146 \\
{[7]}\end{array}$ \\
\hline 4 & & 93 & 88 & 10 & 280 & $\begin{array}{c}144-146 \\
{[7]}\end{array}$ \\
\hline 5 & & 97 & 97 & 10 & 240 & $\begin{array}{c}117-119 \\
{[7]}\end{array}$ \\
\hline 6 & & 93 & 75 & 10 & 300 & $\begin{array}{c}102-104 \\
{[7]}\end{array}$ \\
\hline
\end{tabular}




\begin{tabular}{|c|c|c|c|c|c|c|}
\hline \multirow{2}{*}{ Entry } & \multirow{2}{*}{ Product } & \multicolumn{2}{|c|}{ Yield $(\%)^{\mathrm{c}}$} & \multicolumn{2}{|c|}{ Time (min.) } & \multirow{2}{*}{$\begin{array}{c}\text { m.p. }\left({ }^{\circ} \mathrm{C}\right) \\
{[\text { Ref.] }}\end{array}$} \\
\hline & & $\mathrm{MW}^{\mathrm{a}}$ & r.t. & MW & r.t. & \\
\hline 8 & & 91 & 53 & 15 & $24 \mathrm{~h}$ & $\begin{array}{c}211-213 \\
{[7]}\end{array}$ \\
\hline 9 & & 93 & 85 & 15 & $24 \mathrm{~h}$ & $\begin{array}{c}164-166 \\
{[7]}\end{array}$ \\
\hline 10 & & 73 & 67 & 15 & $24 \mathrm{~h}$ & $\begin{array}{c}222-223 \\
{[7]}\end{array}$ \\
\hline 11 & & 98 & 95 & 10 & 300 & $\begin{array}{c}127-128 \\
{[12]}\end{array}$ \\
\hline 12 & & 98 & ---- & 15 & ----- & $251-253$ \\
\hline
\end{tabular}

a All reactions were carried out using $0.75 \mathrm{mmol}$ of benzyl azide, $0.75 \mathrm{mmol}$ of phenylacetylene and $1 \mathrm{~mL}$ of Et $\mathrm{t}_{3} \mathrm{~N}$ in $2 \mathrm{~mL}$ of ${ }^{i} \mathrm{Pr}-\mathrm{OH} / \mathrm{H}_{2} \mathrm{O}$ $(1: 1)$ at $100 \mathrm{~W}$ and $125^{\circ} \mathrm{C}$.

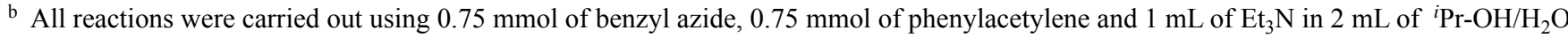
$(1: 1)$ at room temperature.

$c$ isolated yields.

layer chromatography (TLC) was performed on glass plates coated with silica gel 60 F254 and visualized by UV (254 nm). Flash column chromatography was performed using Merck silica gel (230-240 mesh). Melting points were measured in open capillary tubes on a Büchi Melting Point B-540 apparatus and have not been corrected. ${ }^{1} \mathrm{H}$ and ${ }^{13} \mathrm{C}$ NMR spectra were recorded on Varian VNMRS 400 (400 and $100 \mathrm{MHz}$ ) spectrometer. Chemical shifts $(\delta)$ are indicated in ppm downfield from inter- nal TMS used as a reference; coupling constants $(\mathrm{J})$ are given in Hz. IR spectra were measured on a Perkin Elmer GX FT-IR. High resolution mass spectra were obtained with an Agilent G1969A spectrometer. All microwave irradiation experiments were carried out in a CEM-Discover mono-mode microwave apparatus, operating at a frequency of $2.45 \mathrm{GHz}$ with continuous irradiation power from 0 to $100 \mathrm{~W}$ utilizing the standard absorbance level of $300 \mathrm{~W}$ maximum power. 


\section{General procedure for the preparation of 1,2,3-triazoles at room temperature}

In a $50 \mathrm{~mL}$ round-bottomed flask containing a magnetic stirring bar was placed 1 equiv. of azide in $2 \mathrm{~mL}$ of a mixture of 1 $\mathrm{mL}$ of $\mathrm{H}_{2} \mathrm{O}$ and $1 \mathrm{~mL}$ of isopropanol as solvent, followed by the addition of 1 equiv. of alkyne, 0.10 equiv. of $\mathrm{CuSO}_{4}, 0.20$ equiv. of phenylboronic acid, and $1.0 \mathrm{~mL}^{\text {of }} \mathrm{Et}_{3} \mathrm{~N}$. The resulting solution was stirred at room temperature for 5-24 h, followed by extraction with EtOAc $(3 \times 25 \mathrm{~mL})$. The collected organic layers were dried with $\mathrm{MgSO}_{4}$ and the solvent was removed under vacuum to give the corresponding triazole. After removal of ethyl acetate, the crude residue was purified by column chromatography (EtOAc/hexane) to afford 1,2,3-triazoles.

\section{General procedure for the preparation of 1,2,3-triazoles by microwave irradiation}

In a MW tube equipped with a magnetic stirrer was placed 1 equiv. of azide in $2 \mathrm{~mL}$ of a mixture of $1 \mathrm{~mL}$ of $\mathrm{H}_{2} \mathrm{O}$ and $1 \mathrm{~mL}$ of isopropanol as solvent, followed by the addition of 1 equiv. of alkyne, $\mathrm{CuSO}_{4}(10 \mathrm{~mol} \%)$, phenylboronic acid (20 mol\%), and $1.0 \mathrm{~mL}$ of $\mathrm{Et}_{3} \mathrm{~N}$. This tube was sealed, and the content was subjected to focused microwave irradiation at $100 \mathrm{~W}$ for 10 or $15 \mathrm{~min}$ at $125^{\circ} \mathrm{C}$. Then the reaction mixture was diluted with ethyl acetate and washed with a saturated solution of $\mathrm{NH}_{4} \mathrm{Cl}$, the organic phase was collected, dried with $\mathrm{MgSO}_{4}$, filtered and the solvent was vacuum removed. The crude product was purified by crystallization to afford 1,2,3-triazoles.

Compound $\mathbf{3 a}, \mathbf{3 b}, \mathbf{3 c}, \mathbf{3 d}, \mathbf{3 e}, \mathbf{3 f}, \mathbf{3 g}, \mathbf{3 h}, \mathbf{3 i}, \mathbf{3 j}$ and $\mathbf{3 k}$ are known, and their spectra are consistent with the literature data (Table 3).

2-(2-methoxyphenyl)-5-(4-((2-(5-nitrobenzoxazol-2-yl) phenoxy)methyl)-1H-1,2,3-triazol-1-yl)benzoxazole (3l). White solid: $\mathrm{mp} 251-253{ }^{\circ} \mathrm{C}$; yield: $0.11 \mathrm{~g}(98 \%)$. IR $(\mathrm{KBr}) ; v_{\text {max }}$ $2925,1603,1532,1494,1263,1352,1021,746 \mathrm{~cm}^{-1} ;{ }^{1} \mathrm{H}$ NMR (400 MHz, DMSO-d 6 ) $\delta 9.01$ (s, 1H, H-5”), 8.65 (d, $1 \mathrm{H}, J=2.4 \mathrm{~Hz}, \mathrm{H}-14$ "), 8.30 (m, 2H, H-4, H-6), 8.07 (m, 2H, H-16", H-17"), 7.97 (m, 2H, H-7, H-10"), 7.62 (m, 3H, H-6', H-8”, H-11"), 7.29 (d, 1H, $J=8.4 \mathrm{~Hz}, \mathrm{H}-3$ '), 7.21 (t, 1H, $J=$ $7.5 \mathrm{~Hz}, \mathrm{H}-5$ ') 7.15 (td, $1 \mathrm{H}, J=8.0 \mathrm{~Hz}, J=2.5 \mathrm{~Hz}, \mathrm{H}-9$ '), 5.73 (s, 2H, H-6"), 3.93 (s, 3H, H-7'); ${ }^{13} \mathrm{C}$ NMR (DMSO- $d_{6}$, $100 \mathrm{MHz}) \delta 163.5$ (C-2), 162.7 (C-13”), 157.3 (C-7”), 157.1 (C-2'), 156.1 (C-17a"), 150.4 (C-8a), 150.0 (C-13a"), 144.4 (C-4”), 142.4 (C-3a), 141.5 (C-6'), 137.7 (C-11"), 133.6 (C4'), 132.4 (C-9"), 129.7 (C-5), 123.1 (C-6), 121.7 (C-16"), 121.5 (C-10"), 121.0 (C-5"), 120.3 (C-15"), 119.9 (C-4), 119.1 (C-3'), 117.3 (C-8”), 116.6 (C-14”), 115.2 (C-17”), 111.5 (C-7), 110.6 (C-12”), 109.2 (C-1'), 72.6 (C-6”), 56.1 (C-7'); HRMS (ESI) calcd for $\mathrm{C}_{30} \mathrm{H}_{20} \mathrm{~N}_{6} \mathrm{O}_{6}(\mathrm{M}+\mathrm{H})^{+}$ 561.1444 , found 561.1521 .

\section{Acknowledgements}

We are indebted to Dr. Joseph M. Muchowski for friendly, helpful discussions and to CONACyT for financial support (grant CB-2012-01-182415). One of the authors (J. E. de la Cerda-Pedro) thanks-CONACyT for a scholarship (239377).

\section{References (and notes)}

1. For a special issue dedicated to applications of click chemistry see. Ed. by: Finn, M. G. and Fokin, V.V. Chem. Soc. Rev. 2010, 39, 1221-1222.

2. a) Meldal, M.; Tornøe, C. W. Chem. Rev. 2008, 108, 2952-3015; b) Bock, V. D.; Hiemstra, H.; van Maarseveen, J. H. Eur. J. Org. Chem. 2006, 51-68; c) Rostovtsev, V. V.; Green, L. G.; Fokin, V. V.; Sharpless, K. B. Angew. Chem. Int. Ed. 2002, 41, 2596-2599; d) Tornøe, C. W.; Christensen, C.; Meldal, M. J. Org. Chem. 002, 67, 3057-3064.

3. a) Lewis, W. G.; Green, L. G.; Grynszpan, F.; Radić, Z.; Carlier, P. R.; Taylor, P.; Finn, M. G.; Sharpless, K. B. Angew. Chem. Int. Ed. 2002, 41, 1053-1057; b) Tron, G. C.; Pirali, T.; Billington, R. A.; Canonico, P. L.; Sorba, G.; Genazzani, A. A. Med. Res. Rev. 2008, 28, 278-308; c) Lee, T.; Cho, M.; Ko, S.-Y.; Youn, H.-J.; Baek, D. J.; Cho, W.-J.; Kang, C.-Y.; Kim, S. J. Med. Chem. 2007, 50, 585-589; d) Maurya, S. K.; Gollapalli, D. R.; Kirubakaran, S.; Zhang, M.; Johnson, C. R.; Benjamin, N. N.; Hedstrom, L.; Cuny, G. D. J. Med. Chem. 2009, 52, 4623-4630; e) Kold, H. C.; Sharpless, K. B. Drug Discovery Today 2003, 8, 1128-1137; f) Puig-Basagoiti, F.; Qing, M.; Dong, H.; Zhang, B.; Zou, G.; Yuan, Z.; Shi, P.-Y. Antiviral Res. 2009, 83, 71-79; g) Guezguez, R.; Bougrin, K.; Akri, K. E.; Benhida, R. Tetrahedron Lett. 2006, 47, 4807-4811.

4. Tao, C. Z.; Cui, X.; Li, J.; Liu, A. X.; Liu, L.; Guo, Q. X. Tetrahedron Lett. 2007, 48, 3525-3529.

5. García, M. A.; Ríos, Z. G.; Gonzáles, J.; Pérez, V. M.; Lara, N.; Fuentes, A.; Gonzáles, C.; Corona, D.; Cuevas-Yañes, E. Lett. Org. Chem. 2011, 8, 701-706.

6. Mohammed, S.; Padala, A. K.; Dar, B. A.; Singh, B.; Sreedhar, B.; Vishwakarma, R. A.; Bharate, S. B. Tetrahedron. 2012, 68, 8156-8162.

7. de la Cerda-Pedro, J. E.; Amador-Sánchez, Y. A.; Cortés-Hernández, M.; Pérez-Pérez, J.; Rojas-Lima, S.; López-Ruiz, H. Heterocycles. 2014, 89, 27-41.

8. Bull, S. D.; Davidson, M. G.; van den Elsen, J. M. H.; Fossey, J. S.; Jenkins, A. T. A.; Jiang, Y -B.; Kubo, Y.; Marken, F.; Sakurai, K.; Zhao, J.; James, T. D. Acc. Chem. Res. 2013, 46, 312-326.

9. Chen, T.; Huang, Q.; Luo, Y.; Hu, Y.; Lu, W. Tetrahedron Lett. 2013, 54, 1401-1404.

10. Sawant, S. D.; Hudwekar, A. D.; Kumar, K. A. A.; Venkateswarlu, V.; Singh, P. P.; Vishwakarma, R. A. Tetrahedron Lett. 2014, 55, 811-814.

11. a) Mukherjee, N.; Ahammed, S.; Bhadra, S.; Ranu, B. C. Green Chem. 2013, 15, 389-397; b) Kaboudin, B.; Abedi, Y.; Yokomatsu, T. Org. Biomol. Chem. 2012, 10, 4543-4548.

12. López-Ruiz, H.; de la Cerda-Pedro, J. E.; Rojas-Lima, S.; PérezPérez, I.; Rodríguez-Sánchez, B. V.; Santillán, R.; Coreño, O. Arkivoc. 2013, iii, 139-164.

13. Suarez A. An. Quími. 2012, 108, 306-313.

14. Angell, Y.; Burgess, K. Angew. Chem. Int. Ed. 2007, 46, 3649-3651.

15. González, J.; Pérez, V. M.; Jiménez, D. O.; López-Valdez, G.; Corona, D.; Cuevas-Yañez, E. Tetrahedron Lett. 2011, 52, 35143517.

16. X-ray crystallographic data (excluding structure factors) for the structures in this paper has been deposited with the Cambridge 
Crystallographic Data Centre as a Supplementary Publication Numbers, CCDC 1007167 No. for 3f, CCDC 1007170 No. for 4, CCDC 1007168 No. for $\mathbf{3 h}$, and CCDC 1007169 No for $\mathbf{3 j}$. Copy of the data can be obtained, free of charge, on application to CCDC, 12 Union Road, Cambridge CB2 1EZ, UK [fax: +44(0) 1223336033 or e-mail: deposit@ccdc.cam.ac.uk].

17. a) Loupy, A. Microwaves in Organic Synthesis. Ed. Wiley-VCH, 2001; b) Hayes, B. L. Microwave synthesis Chemistry at the Speed of light. CEM publishing, 2002; c) Tierney, J.; Lindstrom,
P. Microwave Assisted Organic Synthesis. Ed. Blackwll, 2004; d) Kappe, C. O. Angew Chem. Int. Ed. 2004, 43, 6250-6284.

18. Worrell, B. T.; Malik, J. A.; Fokin, V. V. Science. 2013, 340, $457-$ 460.

19. a) King, A. E.; Brunold, T. C.; Stahl, S. S. J. Am. Chem. Soc. 2009, 131, 5044-5045. b) Srivastava, V. P.; Yadav; D. K.; Yadav, A. K.; Watal, G.; Yadav, L. D. S. Synlett. 2013, 24, 1423-1427. c) Mahanta, A.; Adhikari, P.; Bora, U.; Thakur, A. J. Tetrahedron Lett. 2015, in press. 